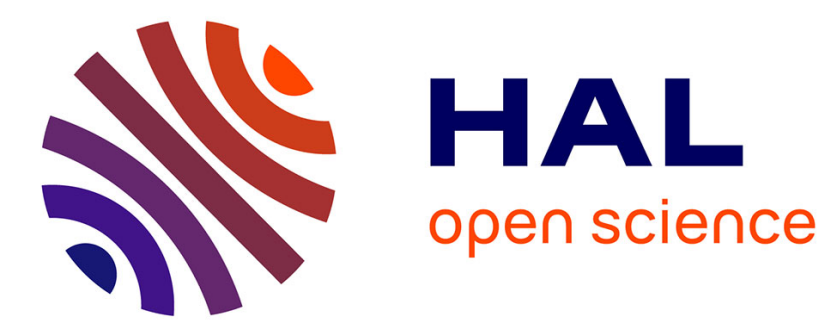

\title{
Laboratory to pilot scale: Microwave extraction for polyphenols lettuce
}

Sandrine Perino, Jean T. Pierson, Karine Ruiz, Giancarlo Cravotto, Farid

Chemat

\section{- To cite this version:}

Sandrine Perino, Jean T. Pierson, Karine Ruiz, Giancarlo Cravotto, Farid Chemat. Laboratory to pilot scale: Microwave extraction for polyphenols lettuce. Food Chemistry, 2016, 204, pp.108-114. 10.1016/j.foodchem.2016.02.088 . hal-02636196

\section{HAL Id: hal-02636196 https://hal.inrae.fr/hal-02636196}

Submitted on 27 May 2020

HAL is a multi-disciplinary open access archive for the deposit and dissemination of scientific research documents, whether they are published or not. The documents may come from teaching and research institutions in France or abroad, or from public or private research centers.
L'archive ouverte pluridisciplinaire HAL, est destinée au dépôt et à la diffusion de documents scientifiques de niveau recherche, publiés ou non, émanant des établissements d'enseignement et de recherche français ou étrangers, des laboratoires publics ou privés. 


\title{
Laboratory to pilot scale: Microwave extraction for polyphenols lettuce
}

\author{
Sandrine Périno ${ }^{\mathrm{a}, *}$, Jean T. Pierson ${ }^{\mathrm{a}}$, Karine Ruiz ${ }^{\mathrm{a}}$, Giancarlo Cravotto ${ }^{\mathrm{b}}$, Farid Chemat ${ }^{\mathrm{a}}$ \\ ${ }^{a}$ Université d'Avignon et des Pays du Vaucluse, INRA, UMR408, GREEN Extraction Team, F-84000 Avignon, France \\ b Dipartimento di Scienza e Tecnologia del Farmaco, Università di Torino, Via P. Giuria 9, 10125 Torino, Italy
}

Keywords:

Green extraction

Solvent-free microwave extraction

Pilot-scale reactor

Lettuce polyphenols

\begin{abstract}
A B S T R A C T
Microwave hydrodiffusion and gravity (MHG) technique has been applied to pilot-scale solvent-free microwave extraction (SFME) of polyphenols from Lettuce sativa. Following the dictates of green extraction and with the aim to save time and energy, the lab-scale knowledge on SFME was exploited for the development of a pilot-scale process. The investigation entailed the optimization of all main parameters (temperature, time, extracted water volume, etc.) and we showed that the polyphenols composition profile under SFME was similar to the classic methods though a bit lower in total content. The energy consumption in the optimized procedure $(30 \mathrm{~min})$ was $1 \mathrm{~W} / \mathrm{g}$ of fresh matrix.
\end{abstract}

\section{Introduction}

Dietary polyphenols occupy a major place in today's food science research (Scalbert \& Williamson, 2000). The high antioxidant activity of polyphenols (RiceEvans, Miller, \& Paganga, 1997) show potential pharmaceutical applications (Duthie, Duthie, \& Kyle, 2000). A varied diet with fruits and vegetables is usually rich in polyphenols, as well as several food supplements manufactured from suitable natural extracts. The healthy effects are well supported by scientific research (Prior, Wu, \& Schaich, 2005), involving improved extraction and purification techniques (Dai \& Mumper, 2010). The use of novel techniques such as ultrasound-assisted extraction (UAE) or supercritical fluid extraction (SFE) are possible alternatives to conventional methods which have limitations and often do not respect the green principles of eco-extraction (Chemat, Vian, \& Cravotto, 2012). The only drawback of UAE is the use of solvent, while SFE apparatuses require economical investment not affordable by most laboratories. Microwave assisted extraction (MAE) is another innovative technique that has proved to be very efficient for the hydrodistillation of essential oils (Bayramoglu, Sahin, \& Sumnu, 2008; Lucchesi, Chemat, \& Smadja, 2004), and that is being investigated at many levels including for the extraction of polyphenols (Proestos \& Komaitis, 2008) The fast volumetric heating by microwave with excellent temperature control avoids gradients and consequently thermal degradation. Like other innovative techniques cited above, MAE aims towards a more ecological protocols. By reducing process

\footnotetext{
* Corresponding author.

E-mail address: sandrine.perino@univ-avignon.fr (S. Périno).
}

time and energy, MAE has proven to be an efficient extraction technique for maceration, soxhlet and other solvent required extraction, including hydrodistillation for the production of essential oils or for the extraction of lipophilic phytoconstituents.

One of the most innovative applications of solvent free microwave extraction (SFME) (Zill-E-Huma, Abert Vian, Maingonnat, \& Chemat, 2009) was microwave hydrodiffusion and gravity (MHG), a technique that pushes the limits of the MAE further towards a greener process (Abert-Vian, Fernandez, Visinoni, \& Chemat, 2008). This technique uses the "in situ" water of the matrix contained in the reactor to extract hydrophilic phytoconstituents. It also softens the matrix tissue and ruptures the cavities where phytochemicals are stored. Heating the in situ water contained in the fresh matrix transfers it outside of the plant material, sweeping phytochemicals along with it. So far MHG technology has been mainly used in lab-scale experiments and proved itself very useful for fresh matrixes. In the search for larger scale production, new pilot microwave reactors have been designed.

We report herein the complete MHG study from laboratory bench scale to pilot scale solvent-free extraction of polyphenols from fresh Lettuce sativa (blonde oak leaf var.). We optimize microwave parameters, monitoring temperature and measuring polyphenol content as it was extracted from the matrix. We use temperature control, extracted water volume and total polyphenol content as tools to evaluate best parameters for rapid and efficient extraction of polyphenols. We demonstrate that MHG is a valuable tool in the preparation of non-degraded polyphenol extract on a laboratory scale, and its larger production in a pilot reactor, which allows a massive reduction in biomass wastes. 


\section{Materials and methods}

\subsection{Plant material and chemicals}

L. sativa, blonde oak leaf var. was bought from local markets and used on the same day to keep freshness and water content to maximum. Quercetin-3-O-glucuronide and Quercetin-3-O-(6"-malo nyl)-glucoside were purchased from Sigma-Aldrich (St. Louis, MO, USA). Other chemicals were of analytical grade and purchased from VWR international (Darmstadt, Germany).

\subsection{Moisture content}

Moisture content was determined with a Moisture analyzer MB35 (Ohaus, Pine Brook, NJ) electric oven at $110^{\circ} \mathrm{C}$.

\subsection{Extraction procedures}

\subsubsection{Laboratory scale microwave hydrodiffusion and gravity (MHG) extraction}

Extraction was performed by MHG apparatus (Milestone EOS-G microwave laboratory oven, Shelton, CT) patented by Chemat et al. (2008). The general procedure was described by Zill-E-Huma et al. (2009). In brief, lettuces of up to $300 \mathrm{~g}$ were washed of soil residue and inserted in a $4 \mathrm{~L}$ Pyrex reactor. Temperature was monitored by sensor optic fibers, which were inserted inside the center of the lettuce and inside the reactor to monitor temperatures both at the core of the matrix and the reactor atmosphere. The extract moves down by diffusion into a condenser that was cooled down to $4{ }^{\circ} \mathrm{C}$. Fractions were collected every $5 \mathrm{~min}$ to evaluate the polyphenols extraction against time of extraction. Power was set between 150 and $550 \mathrm{~W}$. Extraction was continued until overheating was detected. Fractions were stored to $-20^{\circ} \mathrm{C}$ until analysis.

\subsubsection{Conventional solid liquid extraction}

$5 \mathrm{~g}$ of lettuce representing every part of the leaf were finely cut and extracted with $50 \mathrm{~mL}$ of $80 \%$ ethanol solution, in an ultrahomogenizer at $4000 \mathrm{rpm}$ for $5 \mathrm{~min}$. Mixture was filtered on Wattman paper before being stored to $-20^{\circ} \mathrm{C}$.

\subsubsection{Pilot scale MHG extraction}

The MAC-75 apparatus (Fig. 1A) is a multimode microwave reactor. It contains 4 magnetrons $(4 \times 1500 \mathrm{~W}, 2450 \mathrm{MHz})$ with a maximum power of $6000 \mathrm{~W}$ delivered in $50 \mathrm{~W}$ increments. The stainless steel microwave cavity has a capacity of $150 \mathrm{~L}$ and contains a removable, rotating PTFE drum that allows up to $75 \mathrm{~L}$ of plant material to be loaded. The rotation ensures a homogeneous microwave distribution to the material inside the drum. The drum circumference is entirely perforated to allow the vapor and liquid to pass. The cavity has 6 external tube connections (one in the top, one in the bottom and 4 in the sides) and is wrapped in removable thermal insulation. The absorption of microwave power is controlled by sensors placed on wave guides. The system automatically adjusts the power delivered, if absorption is too low. The temperature is monitored by a Resistance Temperature Detector (PT-100) inserted into the cavity. The cavity is able to work in deep vacuum or as an open vessel. Interlocks on the door prevent accidental opening during the process or when the cavity contains liquid. The device is controlled by an industrial touch screen control terminal with an intuitive graphic user interface. For the purpose of this study, ten lettuces for a total weight of approximately $4 \mathrm{~kg}$ were processed with a maximum power of $4000 \mathrm{~W}$, until it was evident that all available water had been extracted.

\subsection{Determination of the total extracted polyphenol content (TEPC)}

TEPC was estimated colorimetrically using the Folin-Ciocalteu method (Singleton \& Rossi, 1965), with a kit (SEPPAL (Isitec-lab), France) especially suitable for TEPC (total phenolic content) measurement of food products. This kit includes reagent A (modified Folin-Ciocalteu reagent), reagent $\mathrm{B}$ (alkaline buffer) and a gallic acid solution $(3 \mathrm{~g} / \mathrm{L})$. A small volume $(20 \mu \mathrm{L})$ of $\mathrm{H}_{2} \mathrm{O}$ (blank), gallic acid solution (standard) adjusted with $180 \mu \mathrm{L}$ of distilled water and $200 \mu \mathrm{L}$ the extract (sample) was mixed with reagent $A$ $(2 \mathrm{~mL})$. After $1 \mathrm{~min} 1 \mathrm{~mL}$ of reagent B was added in all samples. The mixtures were allowed to stand for 30 min in the dark at room temperature. Then, their absorbance was measured at $760 \mathrm{~nm}$. TEPCs were calculated by using the following formula:

TEPCs $=\frac{3 *(\text { sample absorbance }- \text { blank absorbance })}{(\text { standard absorbance }- \text { blank absorbance })}$

The results were expressed as mg gallic acid equivalent/100 $\mathrm{g}$ of fresh weight (mg GAE/100 g FW).

\subsection{High performance liquid chromatography (HPLC) analysis of polyphenols}

HPLC analyses of polyphenols were performed using a Waters (Milford, MA) HPLC system consisting of a Waters 600E pump, a Waters 717 manual injector rheodyne, a Waters 2996 photodiode array detector. The HPLC pumps, manual injector rheodyne, column temperature, and diode array system were monitored and controlled by using Waters Empower 2 Chromatography Data software program. The wavelength used for the quantification of the lettuce polyphenols with the diode detector was $360 \mathrm{~nm}$. The chromatographic separation was carried out on a Purospher Star RP-18 end-capped column $(250 \mathrm{~mm} \times 4 \mathrm{~mm}$ I.D.; $5 \mu \mathrm{m}$ particle size from VWR), with a RP18 guard column $(4 \mathrm{~mm} \times 4 \mathrm{~mm}$ I.D.; $5 \mu \mathrm{m}$ particle size also from VWR international (Darmstadt, Germany)). The end-capped column and guard column were held at $37^{\circ} \mathrm{C}$ and the flow rate was set at $1 \mathrm{~mL} / \mathrm{min}$. The mobile phase consisted of two solvents: (A) acidified water ( $0.5 \%$ formic acid) and (B) acetonitrile $(0.5 \%$ formic acid). The solvent gradient used was the following: 0 min $5 \%$ (B); 0-3 min 35\% (B); 3-17 $\mathrm{min}, 60 \%$ (B); 17-20 min $100 \%$ (B); $20-25 \mathrm{~min}$ isocratic $100 \%$ (B), $25-30$ min $5 \%$ (B), 30 $35 \mathrm{~min}$ isocratic $5 \%$. The injection volume was $20 \mu \mathrm{L}$. Identification of flavonoids was done by comparing the elution order and UVvisible spectra. Quantification was carried out by using the external standards (Quercetin-3-O-glucuronide and Quercetin-3-O-(6"malonyl)-glucoside) of known concentration. Peak areas were used to quantify the compounds in the sample. A linear regression analysis was carried out on the data of the peak area versus concentration. Linear calibration curves of the standards ranging from 10 to $200 \mathrm{mg} / \mathrm{L}$ were obtained with good linearity and $R^{2}$ values which were more than $99.5 \%$ accurate for all the standards. Final concentrations of different components were calculated in mg/100 g FW.

\section{Results and discussion}

\subsection{MHG parameters study}

As first we evaluated the penetration depth of microwave through the vegetal matrix by temperature measurements. Briefly, following the temperature evolution, 3 phases can be observed. The first phase is a quick heating phase characterized in Fig. 2 by a segmented line with a constant slope varying with the power used.

During this phase, the core reaches the temperature of $100{ }^{\circ} \mathrm{C}$ more or less rapidly as a function of the corresponding power 
Version définitive du manuscrit publiée dans / Final version of the manuscript published in :

Food Chemistry (2016), Vol. 204, p. 108-114, DOI: 10.1016/j.foodchem.2016.02.088

Journal homepage : www.elsevier.com/locate/foodchem
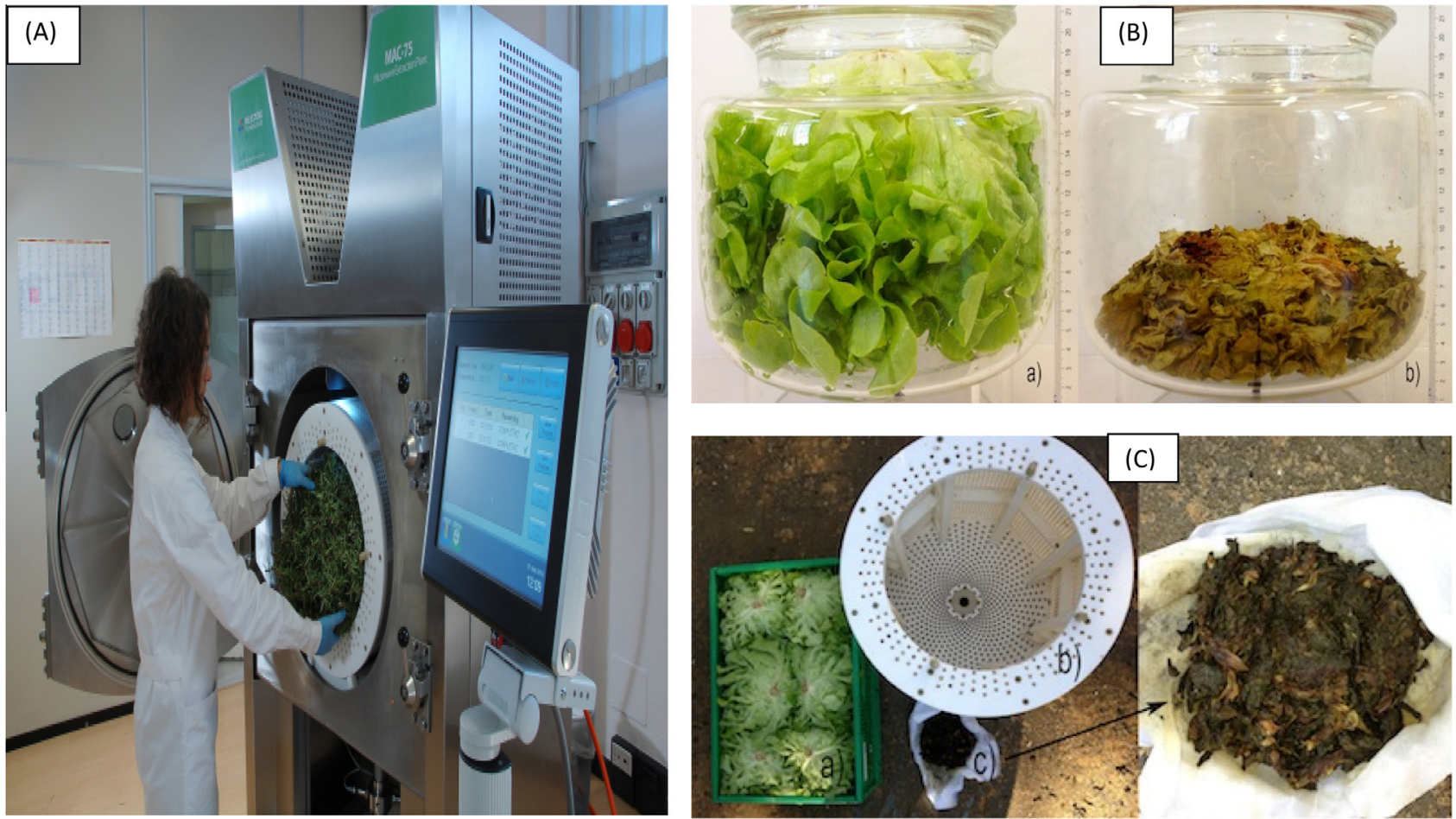

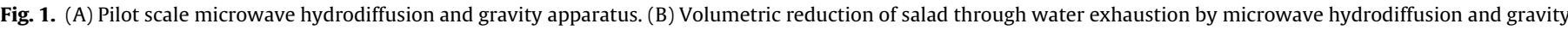

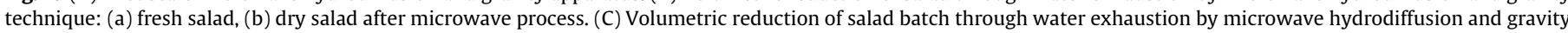
technique, pilot reactor, (a) fresh salad batch, (b) reactor, (c) biomass after MHG reduction.



Fig. 2. Heating phenomenon of microwaves in lettuce samples at different powers.

applied. Heating rates could be determined according to the slope of the segmented line calculated (Prism 6.0, Graphpad) and are as follows: $2.035^{\circ} \mathrm{C} / \min (50 \mathrm{~W}), 7.754^{\circ} \mathrm{C} / \min (150 \mathrm{~W}), 10.99^{\circ} \mathrm{C} / \mathrm{min}$ $(250 \mathrm{~W}), 10.82^{\circ} \mathrm{C} / \min (300 \mathrm{~W}), 12.52^{\circ} \mathrm{C} / \min (350 \mathrm{~W}), 15.47^{\circ} \mathrm{C} /$ $\min (450 \mathrm{~W})$, and $22.54^{\circ} \mathrm{C} / \min (550 \mathrm{~W})$. Upon reaching $100^{\circ} \mathrm{C}$ (the second phase) does not evolve during the extraction of "in situ" water that was moved downward with gravity. As explained by Zill-E-Huma et al., 2009, after the end of the extrac- tion of in situ water, the temperature rises again very quickly and corresponds to the burning phase (phase 3).

\section{2. "In situ" water extraction}

Volume of water extracted was plotted against time (Fig. 3). As it was measured, the water content in $300 \mathrm{~g}$ of blonde oak leaf is on average $94.5 \%$, and is comparable to the literature for this variety of 


\section{Extracted water vs time}

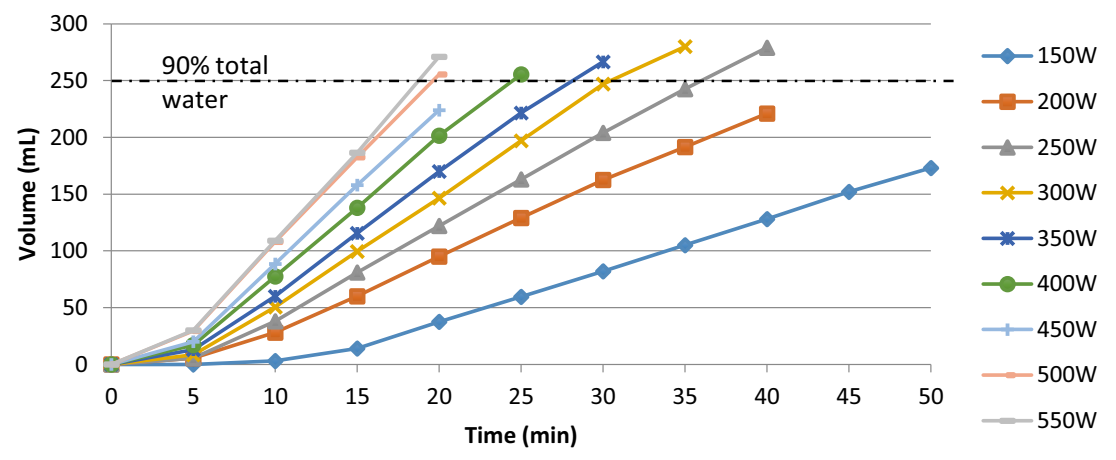

Fig. 3. Extraction curves obtained at different powers showing different stages of extraction.

L. sativa, we can evaluate the total "in situ" water up to $283.5 \mathrm{~g}$ of water. We should expect roughly $280 \mathrm{~mL}$ representing $100 \%$ of "in situ" water at 250-300 W. It is noticeable that to avoid burning and subsequent degradation of polyphenols, some total water content did not reach $280 \mathrm{~mL}$ before the core of the lettuce started burning but more than $80 \%$ of water was extracted for all lettuce except for extremely low power and extremely high power.

At lower power $(150-200 \mathrm{~W})$ the time was not sufficient to extract most water. Upon completion of the cycle, the lettuce was still wet and more water could be extracted. For cycles with power above $400 \mathrm{~W}$, the extraction process is not quick enough before the burning phase happens and as the outer parts of the matrix were still wet, the center was burned and water could still be extracted. Although this was even more visible for $450 \mathrm{~W}$, this is a general observation. We explain this due to the very variable nature of the natural matrices.

For a power set between 250 and $350 \mathrm{~W}$, the cycle led to almost total depletion of water from the matrices leaving a dry, crispy biomass. Those powers are more suitable for safe extraction of total "in situ" water without causing any damage to the matrices that could end in phytochemical degradation.

The extraction of water is linear for all power once induction is completed. Unlike onions, where water drops appeared only when the induction phase was completed, the lettuce matrix is more fragile and releases immediately available water before reaching $100{ }^{\circ} \mathrm{C}$. The induction phase then starts after around $10 \mathrm{~min}$ for all power settings ( $15 \mathrm{~min}$ for $150 \mathrm{~W}$ ).

\subsection{Volumetric analysis}

To represent the water content exhaustion and extraction of lettuce "in situ" water obtained after microwave treatment, we measured the average volume of a lettuce contained in the reactor before and after the extraction. The reactor volume containing a lettuce was approximately $4 \mathrm{~L}$. As shown on Fig. 1B, the volume of biomass obtained after exhaustion of "in situ" water was considerably reduced compared to the volume of a fresh lettuce. Reduction was evaluated approximately at one fifth $(1 / 5)$ of the initial volume.

On the pilot equipment, the content of 10 lettuces occupying the total reactor volume were processed. As shown in Fig. 1C, the lettuce batch (a) was processed in the reactor (b) to obtain the biomass residue (c) which was more than 20 times smaller in volume compared to the initial fresh biomass.

\subsection{Microwave extracted polyphenol contents}

In order to quantify polyphenol extraction over time, we collected in the laboratory MHG equipment extracted water at
5 min interval. The Total Phenolic Content (TPC) of each fraction was then measured according to the Folin-Ciocalteu test, and total extracted polyphenol content (TEPC) was calculated, both total and over time. As for all vegetal material, content in polyphenol varies greatly from one batch to the next. As a result we present here both the calculated content and the normalized content. Results are presented in Fig. 4. Lowest power rating $(150 \mathrm{~W})$ is characterized in a slow extraction of polyphenols over time, with a highest TEPC between 20 and $30 \mathrm{~min}$.

Increasing the level of power used (200 and $250 \mathrm{~W}$ ) shifted maximum TEPC between 15 and $25 \mathrm{~min}$, but extraction of polyphenols is continued for a total of $35 \mathrm{~min}$. Upon reaching 300 and $350 \mathrm{~W}$ power used, we measured on graphs (b) and (c) that polyphenol extraction reaches its maximum between 5 and $15 \mathrm{~min}$, with a maximum TEPC around $30 \mathrm{~min}$. After this point it is clear that, both for the fractionated extracted polyphenol content (a), and the TEPC (b and c), polyphenol extraction quickly reaches a maximum rate. Higher used powers $(400,450,500$ and $550 \mathrm{~W})$ did not further increase extraction rates. Although, we observed that the TEPC for those powers did not yield a higher quantity of polyphenols. Using higher powers did not seem to increase the extraction process anymore but made the extraction more difficult to control. Indeed, at high powers, the heating is not homogeneous enough and degradation of the matrix can occur rapidly, as the process gets out of control. At those powers, although the kinetic was similar for all replicates, reproducibility in term of polyphenol quantity and volume of extracted water was not of sufficient level.

MHG TEPC was quantified as an average of $3.13 \mathrm{mg}$ of gallic acid equivalent per $100 \mathrm{~g}$ of fresh weight (FW) lettuce. As a comparison, with extraction performed with conventional method there was extracted $101 \mathrm{mg} / 100 \mathrm{~g}$. This is an approximately 33 times less extracted polyphenol. This difference is explained by the difference in methods and the absence of extraction solvent. Per comparison, our variety of blonde oak leaf lettuce was particularly poor in terms of polyphenol content compared to those reported in the literature (Llorach, Martínez-Sánchez, Tomás-Barberán, Gil, \& Ferreres, 2008).

Using the pilot scale equipment, total extracted volume was evaluated up to $3.650 \mathrm{~L}$. The TEPC of the whole lettuce juice was calculated to be equal to $6.71 \mathrm{mg} / 100 \mathrm{~g}$ FW. This major difference with the laboratory scale MHG comes from the fact that the pilot scale equipment includes mechanical rotation, which enhances both diffusion of solute into the "in situ" water, and extraction of "in situ" water, as well as acting as a stirrer, which is absent in the small reactor. It is expected that most polyphenol content would be extracted at the start of the extraction process as well, but that a mechanical stirring is essential to the hydrodiffusion of phytoconstituents. 




b)

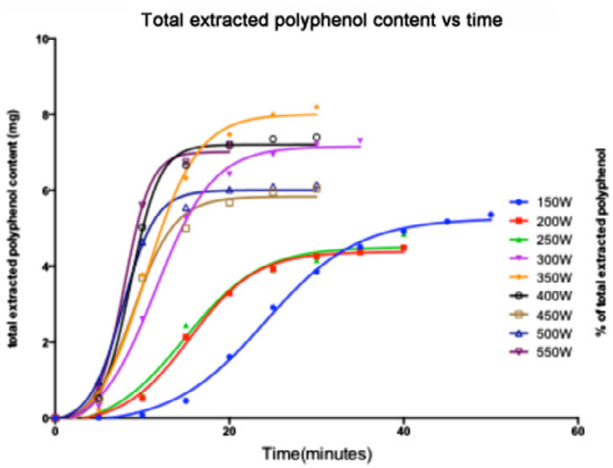

c)

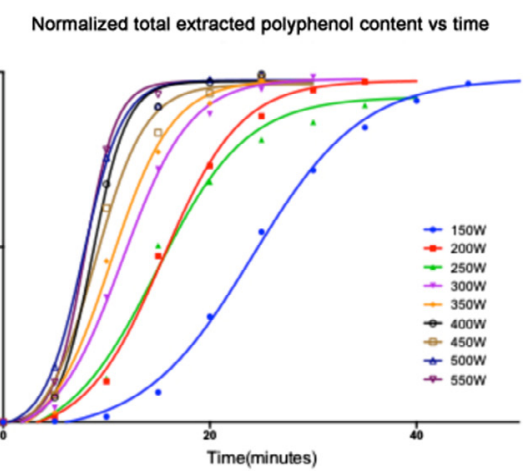

\subsection{HPLC analysis}

For all powers the fraction that contained the highest polyphenols concentration was analyzed for polyphenols composition. Content was found to be similar for all powers and five compounds were predominantly detected at $355 \mathrm{~nm}$ wavelength. To obtain the best resolution possible aqueous extracts were concentrated for the purpose of determining putative identity or, when a commercially pure compound was available, to calculate the concentration in the extract. Fig. 5 shows the representative chromatogram of such extracts.

Compounds 3 and 5 were identified by comparison with standards as quercetin-3-0-(6"-malonyl)-glucoside (3) and quercetin3-O-glucuronide (5) with respective concentration of 3.3 and $8.1 \mathrm{mg} / \mathrm{L}$. By comparison with elution order and UV spectra other compounds were putatively identified as follow in Table 1.

Compounds detected in blonde oak leaf variety reported from the literature (Ferreres, Gil, Castañer, \& Tomás-Barberán, 1997; García-Macías et al., 2007; Heimler, Isolani, Vignolini, Tombelli, \& Romani, 2007; Llorach et al., 2008) confirm our identifications for the quercetin derivatives as major components of lettuce phytoconstituents including glucuronide and malonyl glucoside substitutions. The luteolin derivative suggested by the maximal absorbance peaks ( $347 \mathrm{~nm}$ ) is also confirmed by the elution order reported in the literature (Llorach et al., 2008) and is suspected to be the luteolin-7-glucuronide, or the un luteolin-7-glucoside. Compounds that are usually reported in the literature, and that were not detected in our extracts, were the kaempferol derivatives, and acids such as caffeoyl quinic acid, caffeoyl tartaric acids or chicoric acid. The unidentified flavonoid (compound 2) presents characteristics of a methoxylated flavonoid (an absorbance band at $336 \mathrm{~nm}$ ) (Abad-García, Berrueta, Garmón-Lobato, Gallo, \& Vicente, 2009), which has not been reported yet in literature as being one major compound for L. sativa. All major compounds were detected in comparable ranges for all extraction techniques (laboratory and pilot scale MHG and conventional methods) with differences imputable to the different origins of fresh material. The major difference appears to be the absence of Quercetin-3-Oglucuronide in the pilot-MHG extract, which was compensated by a higher absorbance peak for the luteolin derivative. This difference is explained by the batches of lettuces that were used respectively for laboratory scale and conventional extraction methods (batch 1) and pilot scale MHG extraction method (batch 2). The presence of quercetin derivatives as a general rule confirms that 


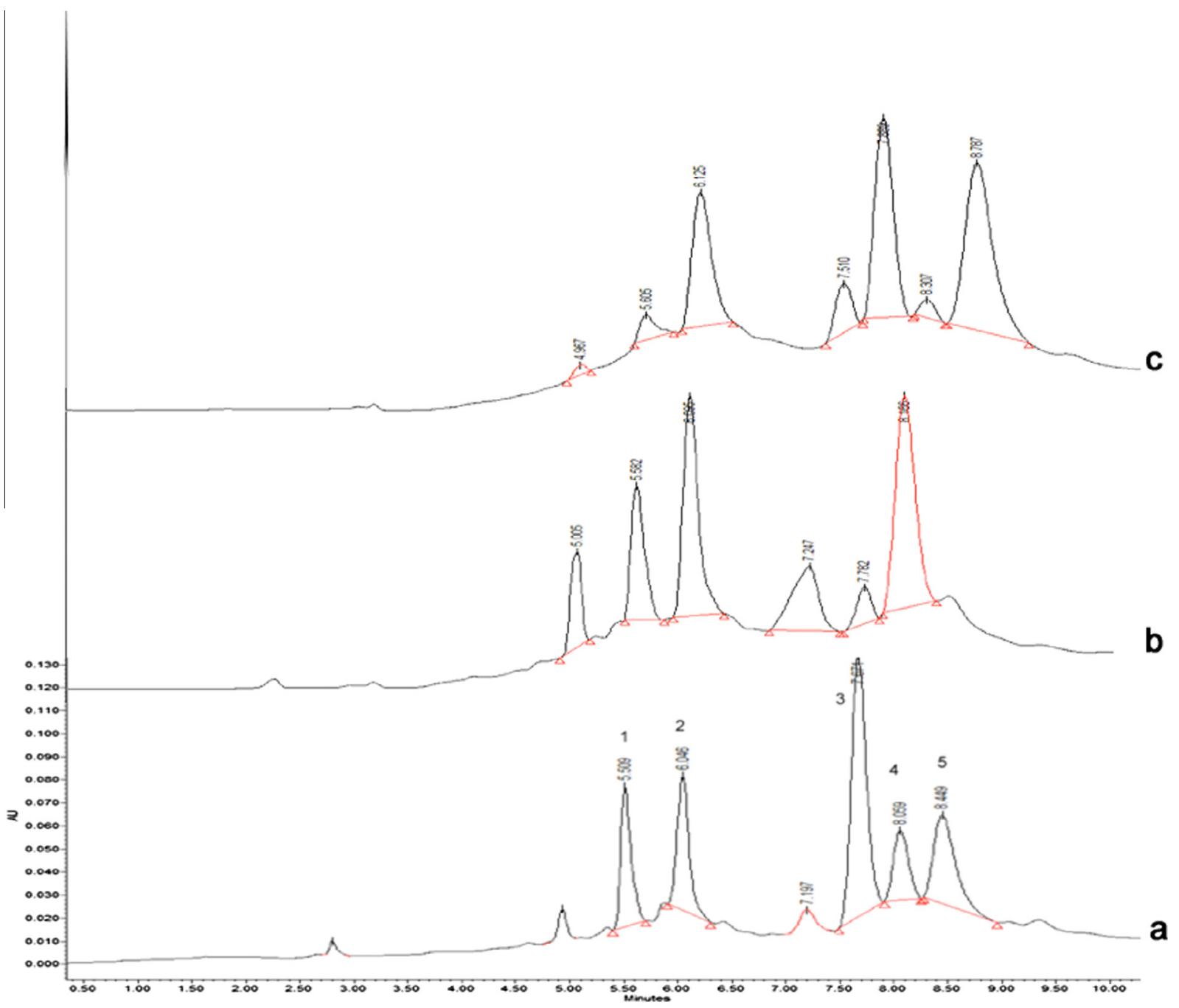

Fig. 5. MHG extracts HPLC chromatogram, $355 \mathrm{~nm}$; (a) laboratory MHG, (b) pilot MHG, (c) conventional method.

Table 1

Comparative phytoconstituent distribution.

\begin{tabular}{|c|c|c|c|c|c|c|}
\hline Peak & R.T. (min) & Putative ID & $\lambda \max (\mathrm{nm})$ & Laboratory MHG (mg/L) & Pilot MHG (mg/L) & Conventional method (mg/L) \\
\hline 1 & 5.5 & Quercetin derivative $^{\mathrm{a}}$ & 252,355 & 2.5 & 2.4 & 0.6 \\
\hline 2 & 6.0 & Flavonoid $^{\mathrm{a}}$ & 252,336 & 2.5 & 4.7 & 2.9 \\
\hline 3 & 7.7 & Quercetin-3-0-(6"-malonyl)-glucoside & 255,355 & 3.3 & 0.12 & 3.9 \\
\hline 4 & 8.1 & Luteolin derivative $^{\mathrm{a}}$ & $253,266,347$ & 1.9 & 5.8 & 0.3 \\
\hline 5 & 8.5 & Quercetin-3-O-glucuronide & 255,355 & 8.1 & N.D. & 5.1 \\
\hline
\end{tabular}

a Expressed as mg/L of quercetin-glucuronide, N.D. not detected.

pilot-scale MHG would extract such compounds comparatively to the laboratory-scale MHG. Cultivation conditions are imputable for the absence of quercetin-3-O-glucuronide.

\section{Conclusions}

MHG has been used for the extraction of polyphenols from the blonde oak leaf lettuce (L. sativa). Laboratory scale extraction protocol was optimized and applied to pilot scale equipment providing a polyphenol extract using a solvent-free technique, respectful of a greener process for the production of natural extracts. Biomass waste was reduced by more than 20 times its size. SFME technique produced an extract with comparable polyphenols profile compared to conventional methods. Pilot- scale equipment provided a higher total polyphenol content compared to that of laboratory scale, due to the mechanical stirring of the matrix leading to a more effective hydrodiffusion phenomena. The best parameters for optimal utilization of SFME with a fragile matrix like lettuce should be chosen at $1 \mathrm{~W}$ per gram, this result is in accord with previous studies in our laboratory with regard to of extraction control and to avoid matrix degradation.

\section{References}

Abad-García, B., Berrueta, L., Garmón-Lobato, S., Gallo, B., \& Vicente, F. (2009). A general analytical strategy for the characterization of phenolic compounds in fruit juices by high-performance liquid chromatography with diode array detection coupled to electrospray ionization and triple quadrupole mass spectrometry. Journal of Chromatography A, 1216(28), 5398-5415. 
Version définitive du manuscrit publiée dans / Final version of the manuscript published in :

Food Chemistry (2016), Vol. 204, p. 108-114, DOI: 10.1016/j.foodchem.2016.02.088

Journal homepage : www.elsevier.com/locate/foodchem

Abert-Vian, M. A., Fernandez, X., Visinoni, F., \& Chemat, F. (2008). Microwave hydrodiffusion and gravity, a new technique for extraction of essential oils. Journal of Chromatography A, 1190(1-2), 14-17.

Bayramoglu, B., Sahin, S., \& Sumnu, G. (2008). Solvent-free microwave extraction of essential oil from oregano. Journal of Food Engineering, 88(4), 535-540.

Chemat F., Abert Vian M., Visinoni F. (2008), Microwave hydro-diffusion for isolation of natural products. European Patent, EP 1,955,749 A1.

Chemat, F., Vian, M. A., \& Cravotto, G. (2012). Green extraction of natural products: Concept and principles. International Journal of Molecular Sciences, 13(7), 8615-8627.

Dai, J., \& Mumper, R. J. (2010). Plant phenolics: Extraction, analysis and their antioxidant and anticancer properties. Molecules (Basel, Switzerland), 15(10), 7313-7352.

Duthie, G., Duthie, S., \& Kyle, J. (2000). Plant polyphenols in cancer and heart disease: Implications as nutritional antioxidants. Nutrition Research Reviews, 13 (1), 79-106.

Ferreres, F., Gil, M., Castañer, M., \& Tomás-Barberán, F. (1997). Phenolic metabolites in red pigmented lettuce (Lactuca sativa). Changes with minimal processing and cold storage. Journal of Agricultural and Food Chemistry, 45(11), 4249-4254.

García-Macías, P., Ordidge, M., Vysini, E., Waroonphan, S., Battey, N., Gordon, M. et al. (2007). Changes in the flavonoid and phenolic acid contents and antioxidant activity of red leaf lettuce (Lollo Rosso) due to cultivation under plastic films varying in ultraviolet transparency. Journal of Agricultural and Food Chemistry, 55(25), 10168-10172.
Heimler, D., Isolani, L., Vignolini, P., Tombelli, S., \& Romani, A. (2007). Polyphenol content and antioxidative activity in some species of freshly consumed salads. Journal of Agricultural and Food Chemistry, 55(5), 1724-1729.

Llorach, R., Martínez-Sánchez, A., Tomás-Barberán, F., Gil, M., \& Ferreres, F. (2008). Characterisation of polyphenols and antioxidant properties of five lettuce varieties and escarole. Food Chemistry, 108(3), 1028-1038.

Lucchesi, M. E., Chemat, F., \& Smadja, J. (2004). An original solvent free microwave extraction of essential oils from spices. Flavour and Fragrance Journal, 19(2), 134-138.

Prior, R. L., Wu, X., \& Schaich, K. (2005). Standardized methods for the determination of antioxidant capacity and phenolics in foods and dietary supplements. Journal of Agriculture and Food Chemistry, 53(10), 4290-4302.

Proestos, C., \& Komaitis, M. (2008). Application of microwave-assisted extraction to the fast extraction of plant phenolic compounds. LWT - Food Science and Technology, 41(4), 652-659.

RiceEvans, C., Miller, J., \& Paganga, G. (1997). Antioxidant properties of phenolic compounds. Trends in Plant Science, 2(4), 152-159.

Scalbert, A., \& Williamson, G. (2000). Dietary intake and bioavailability of polyphenols. Journal of Nutrition, 130(8S Suppl.), 2073S-2085S.

Singleton, V. L., \& Rossi, J. A. (1965). Colorimetry of total phenolics with phosphomolybdicphosphotungstic acid reagents. American Journal of Enology and Viticulture, 16, 144-158.

Zill-E-Huma Abert Vian, M., Maingonnat, J. F., \& Chemat, F. (2009). Clean recovery of antioxidant flavonoids from onions: Optimising solvent free microwave extraction method. Journal of Chromatography A, 1216(45), 7700-7707. 